\title{
The Correlation between Learners' Logs of Navigations through Online Corpora and Lexical Competence
}

\author{
Serkan ÇELIK* Hafize KESER **
}

\begin{abstract}
The current study investigated the relationship between students' lexical competence and their logs of online corpora embedded to a learning management system. The participants of the study were 68 undergraduate students enrolled in a medical school at a Turkish state university. The instruction was delivered through Moodle. The data collection instruments were a vocabulary knowledge scale and a collocation test both revealing ideal reliability and validity indices. Partial correlation was conducted to analyze the data. Findings revealed that there was a positive correlation between the durations of language learners' navigations of online corpora and their acquisitions of academic words and prepositional phrases.
\end{abstract}

Keywords: Corpus linguistics, corpora, concordance, datadriven learning, learner logs

\footnotetext{
Assist. Prof. Dr. Kirlkkale University, Faculty of Education, Department of Computer Education and Instructional Technologies, Tel: $03123633350 / 1632$

E-mail: serkancelik@kku.edu.tr

Prof. Dr. Ankara University, Faculty of Educational Sciences, Department of Computer Education and Instructional Technologies, Tel: 03123633350 / 1632

E-mail: hafizekeser@yahoo.com
} 


\section{SUMMARY}

Purpose and Significance: In recent years, research in corpora and its basic component, concordances has been providing a solid potential in language learning. Although a significant amount of attention has been attracted towards the corpora based language learning, the relevant literature still posits a lack of experimental research on assessing corpora's effect on language development. The last two decades have seen an increasing interest in the efforts of providing learners with direct interaction with corpora, which is called 'data-driven learning' by Johns (1991). Data-driven learning approach is alleged to have various pros, including fostering autonomous learning, promoting language awareness and noticing skills, and enhancing ability to deal with authentic language materials. However, empirical evidence in support of the theory seems essential to propose a practical framework. On the other hand, numerous innovative web interfaces have been developed which incorporate corpora in a more guided language learning environment. Nevertheless, information and communication technologies can be tremendously motivating for some; it represents an affective barrier for many others. This research aims to explore the correlation between the students' logs of online corpora through a learning management system and their lexical acquisitions of academic words and prepositional phrases.

Methods: As a quasi-experimental model, the current study's participant group was 68 students enrolled in Faculty of Medicine at Ankara University. Instruction was delivered through a learning management system to the participants of the study. Instruments utilized to collect the data were a vocabulary knowledge scale and a collocation test. The statistical method used to analyze the data was partial correlation analysis.

Results: The data obtained pointed out that there is a positive correlation (.32) between both groups' durations they spent through learning management system and their achievement of vocabulary knowledge scale $(p<.05)$. Another positive correlation was observed between the logs and achievements of the learners that studied according to data-driven learning approach. That is to say, the more students spent time through the online corpora the more they performed at the post application of vocabulary knowledge scale. On the other hand, it was concluded that there is no relationship between the length of time that all students spent at the learning management system and the final scores in collocation test $(p>.05)$. Furthermore, it was determined that there is no relationship between the final scores of the students that studied with online dictionary at the collocation 
test and the amount of time spent through learning management system $(\mathrm{p}>.05)$.

Discussion and Conclusion: The main outcome of the study was that navigation time through online learning platform designed according to the language needs of the students had a positive effect on learners' lexical performances in general. Additionally, logs of learners that studied with online corpora tools showed a positive correlation with their post-test performances. However, the positive correlation seen at acquisition of academic words could not be observed at comprehension of the semantic relations among the words. 


\title{
Öğrencilerin Çevrimiçi Derlemlerde Gezinim Süreleri ve Sözcük Edinimleri Arasındaki İlișki
}

\author{
Serkan ÇELIK ${ }^{*} \quad$ Hafize KESER
}

ÖZ. $\mathrm{Bu}$ araştırma, öğrencilerin veri yönlendirmeli öğrenme (VYÖ) yaklaşımı ile çevrimiçi sözlük kullanımı yöntemlerinin yabancı dilde sözcük edinimi boyutunda öğrenci başarısına etkilerini çevrimiçi öğrenme ortamlarında gezinme kayıtları bağlamında araştırmak amacıyla yapılmıştır. Araştırma yarı deneysel araştırma modeline göre yürütülmüştür. Araştırmanın çalışma grubunu, 20082009 öğretim yılında Ankara Üniversitesi Tıp Fakültesinde öğrenim gören 68 öğrenci oluşturmuştur. Çalışmanın deney gruplarına çevrimiçi öğrenme ortamı üzerinden eğitim verilmiştir. Veriler, geçerlik ve güvenirlik çalışmaları yapılmış olan, sözcük bilgisi ölçeği ve ilişkili sözcük bilgisi ölçme aracı ile elde edilmiştir. Elde edilen verilerin çözümlenmesinde, kısmi korelasyon analizi yöntemi kullanılmıştır. Araştırma sonucunda, öğrencilerin öğrenme yönetim sisteminde bulunma süreleri ile sözcük ve ilişkili sözcükleri edinimleri arasındaki ilişki bakımından, bulgulara dayalı olarak öğrencilerin sistemde bulunma süreleri arttıkça, sözcük bilgisi düzeyi ile ilgili ölçümlerden elde ettikleri puanlarda artış olduğu gözlenmiştir.

Anahtar Sözcükler: Derlem dilbilim, derlem, veri yönlendirmeli öğrenme

\footnotetext{
* Yrd. Doç. Dr. Kırıkkale Üniversitesi, Eğitim Fakültesi, Bilgisayar ve Öğretim Teknolojileri Eğitimi Bölümü, Tel: 03123633350 /1632 E-posta: serkancelik@kku.edu.tr

Prof. Dr. Ankara Üniversitesi, Eğitim Bilimleri Fakültesi, Bilgisayar ve Öğretim Teknolojileri Eğitimi Bölümü, Tel: 03123633350 / 1632 E-posta: hafizekeser@yahoo.com.
} 


\section{GİRIŞ}

Derlem ve derlem dilbilim nosyonlarının dil alanını ve uygulamalarını, dilbilim ve dil öğretimi disiplinlerinin kullanım yöntemlerini, kavramsal ve işlevsel olarak 'devrim' boyutunda etkilediği öne sürülmektedir (Hunston, 2002; Meyer, 2002; Sinclair, 2005). Derlem sözcügüü sözlüklerde 'yazılı ve sözlü metinlerden oluşmuş bir koleksiyon' (Oxford Sözlüğü), 'dil çalışmaları alanında kullanılmak üzere oluşturulmuş geniş, yazılı ve sözlü dil gövdesi' (Longman Sözlüğ̈̈), 'belli bir yazarın yazdıklarının tümü' ve 'belli bir konuda yazılanların tümü veya bir dilin durumunu göstermek amacıyla bir araya getirilmiş büyük miktarda yazılı veya bazen de sözlü materyal' (Cambridge Sözlüğ̈̈) olarak tanımlanmaktadır. Sinclair (2005) ise derlemi 'dilbilimsel araştırmalara kaynak oluşturmak amacıyla bir dili mümkün olduğunca temsil edebilme niteliğine sahip elektronik ortamdaki dil parçalarının bir araya getirilmiş şekli' olarak tanımlamıştır. Derlem (Corpus) sözcüğü Latince'deki 'gövde' (body) sözcügünden gelmektedir. Sözcügün çoğulu Latince'de 'corpora' olarak geçmektedir. Sinclair'e (2005) göre derlem, doğal yollardan oluşan dil metinlerinin, bir dilin durumunu ve çeşitliliğini tanımlamak için bir araya getirilmiş dil yapılarının tümüdür. 'Dilbilim ve fonetik sözlügünde' ise derlem 'dilbilimsel tanımlamaların başlangıç noktasında kullanılabilecek bir dilbilimsel veri koleksiyonu' olarak tanımlanmaktadır. McEnery ve Wilson (1997) ise, derlemin elektronik olarak okunabilir formatta ve idealde yazılım paketleri kullanılarak gözlemlenebilir ve incelenebilir olması gerektiğini ifade etmiştir. Diğer taraftan, sözcük listeleri, bir derlem oluşturmak için üretilmiş cümlelerin listesi, aralarında herhangi bir mantıksal örgünün bulunmadığ 1 elektronik metinlerden oluşmuş arşivler, derlem olarak değerlendirilmezler.

Derlem çalışmalarının yaygınlaşması sonucu ortaya çıkmış olan 'derlem dilbilim' alanı geniş ve belirli ölçütlere dayalı olarak formatlanmış özgün dil veritabanlarını incelemek için bilgisayar teknolojisinden yararlanmayı içeren bir dil araştırma yaklaşımıdır. Derlem dilbilimcilerin amaçları dil kullanımının gerçek hayatta nasıl gerçekleştiği ile ilgili olarak tanımlamalar yapmak ve bu tanımlamaları bilgisayar ortamına yüklenmiş geniş dil metinleri koleksiyonlarına dayandırmaktır. Derlem dilbilim alanını tanımlarken bilgisayarlı dilbilim kavramı ile ilişkisine de değinmek gerekmektedir. Ball'a (1996) göre, derlem dilbilim ve bilgisayarlı dilbilim kavramları zaman zaman birbirlerinin yerine kullanılmakla birlikte, önemli bir farklılığa sahiptirler. Derlem dilbilim, bilgisayarı sıklıkla dil verilerini incelemek için kullanırken, bilgisayarlı dilbilim uzmanları araştırmalarını bilgisayarca okunabilir dilbilim verilerine dayandırmak zorundadırlar. Bir başka deyişle, derlem dilbilim alanında derlemdeki veri, çalışmanın esas 
unsurudur. Ancak, bilgisayarlı dilbilim alanında derlemler sadece dilbilim problemlerinin çözümünde bir kaynak olarak kullanılırlar. Meyer (2002) derlem dilbilimi genel dilbilimin altında kendine özgü bir boyutu olan ve giderek bir alt disipline dönüşen bir alan olarak tanımlamaktadır. Teubert (2002) ise derlem dilbilimin araştırma alanlarını dilbilgisi, sözcüksel anlambilim, biçimbilim, anlatımbilim ve jargonlar, sosyo-dilbilim ve öğrenci derlemi araştırmaları olarak, uygulama alanlarını ise sözlükbilim, dilbilgisi ve yabacı dil öğrenme ve öğretme olarak siralamaktadır.

Bir derlemi tanımlayan parametreler: Derlemin türü, kaynağın türü, derlemin boyutları, derlemin etiketlendirilmiş ve etiketlendirilmemiş olması, derlemin statik veya değişken olması, derlemin genel veya alt derlem olması, sözcük sayısı ve türü, sözcük sıklık listeleri elde edilebilmesi, ilişkili sözcük tanımlamaları yapabilmesi, metin analiz yazılımı ile işlenmeye uygunluğu ve ilişkili sözcük tespitine olanak sağlaması olarak tanımlanmaktadır (McEnery ve Wilson, 1997). Derlemler, tasarım amaçlarına göre farklı şekil, boyut ve türde olabilirler. Genel olarak, derlemler, ya sabit bir sözcük miktarı içerirler ve 'İngiliz Ulusal Derlemi' (British National Corpus, BNC) örneğinde olduğu gibi 'sabit boyutlu derlem' veya 'referans derlemi' olarak adlandırılırlar, ya da 'İngilizce bankası' (Bank of English) örneğinde olduğu gibi sürekli yeni metinler eklenerek o dilin güncel durumu incelenmeye çalışılır. İkinci tür genişletilebilir derlemlerdir ve 'gözlem derlemi' veya 'açık uçlu derlem' olarak da adlandırılırlar. Derlem oluşturmada kullanılan metinler ya ilk üretildikleri boyutta kullanılırlar ya da önceden belirlenmiş bir metin uzunluğu esas alınarak derleme dâhil edilirler. Metinlerin bütünlerinden belli bir miktarda bölümünün alınarak oluşturulmuş derlemler dilbilimsel çeşitlilik açısından daha zengin metinlerdir. Bu zenginlik, metinlerin dil ürünü olarak türü (yazılı dil, sözlü dil, roman, tez, söylev), yaratıcılarının cinsel, etnik ve dinsel farklılıkları, alıntılandıkları disiplin (tıp, spor, siyaset, edebiyat) ve sosyo-dilbilimsel (resmi dil, argo, sosyal ortam) farklılıklar ile ilgilidir.

Derlemin içeriği söz konusu olduğunda, genel ve özel olarak iki farklı derlemden söz edilebilir. Genel derlem, Amerikan Ulusal Derlemi örneğinde olduğu gibi bir dili üretildiği bütün ortamlarda tanımlama amacını taşımaktadır. Özel derlem ise Michigan Sözel Akademik İngilizce Derlemi (Michigan Corpus of Academic Spoken English) örneğinde olduğu gibi bir dili üretildiği özel bağlam ve üreten belli kişilerin metinlerinde tanımlamaya çalışır. Derlemler içerik olarak gazetelerden, iş mektuplarından, popüler romanlardan, kitaplardan, dergilerden, yayınlanmış ve yayınlanmamış akademik çalışmalardan alıntılanmış yazılı dil metinlerinden (örn. ODTÜSabancı Türkçe Derlemi), veya kayıt edilmiş veya yazıya dökülmüş resmi 
veya resmi olmayan konuşmalardan, radyo ve TV programlarından, hava durumu bültenlerinden, iş toplantılarından, hatta doğum günü partileri vb.den alıntılanmış sözlü dil metinlerinden oluşturulabilir. Derlemler, bir dili anadili olarak konuşan insanlar tarafindan üretilmiș metinlerden oluşturulabildikleri gibi o dili öğrenen kişiler tarafindan üretilmiş metinlerle de oluşturulabilirler. Bu ikinci türe 'öğrenci derlemi' adı verilmektedir. Derlemlerin sinıflandırılmasında kullanılan bir diğer boyut ise derlemin içerdiği dil sayısıdır. Eğer derlem tek bir dile ait metinlerle oluşturulmuşsa, bunlara 'tek dilli' derlemler, eğer iki ayrı dilde aynı metinlerin çevirileri kullanılarak oluşturulmuşsa, bunlara da 'paralel derlem' denilmektedir (Hunston, 2002; Kennedy, 1998; McEnery ve Wilson, 2001; Meyer, 2002).

Derlem parametrelerinden 'sözcük sıklık listeleri' bir derlemin içinde geçen sözcükleri ve o sözcüklerin sıklıklarını gösteren listelerdir. Sözcük sıklık listeleri, tek bir genel derlem içerisindeki bütün sözcüklerin kullanım sıklıkları ile ilgili bilgi edinmek için kullanılabildiği gibi iki farklı dile ait derlemlerin veya iki alt alana sahip özel derlemlerin arasında sözcük sıklığ 1 ile ilgili veriler elde etmek için de kullanılmaktadır. Örneğin, matematik ve siyaset alanlarında yazılmış doktora tezlerinden oluşturulmuş, iki özel derlemin sözcük sıklık listeleri karşılaştırmalı olarak o alanlarda hangi sözcüklerin ve sözcük türlerinin daha yaygın bir şekilde kullanıldığ önemli veriler sunabilir (Sinclair, 1991). Bir başka deyişle, sözcük sıklık listeleri hem kendi başlarına hem de diğer derlemlere ait listelerle karşılaştııılarak kullanılabilmektedir (Hunston, 2002). Her ikisi de aynı dilbilgisel kategoride yer alan İngilizce'deki 'must' ile 'have to' yapılarının kullanım yaygınlığını tespit etmek, sözcük sıklık listelerinin dilbilgisel kullanımına örnek oluşturabilir. Sözcükbilimsel boyutta ise sıklık listeleri örneğin İngilizce 'deki ‘incredibly' ile 'surprisingly' sıfatlarının yazılı ve sözlü dil ortamlarında kullanım yaygınlığ 1 ve resmilik (kibarlık) mesajları ile ilgili bilgi edinmek için kullanılabilir. Bu örnekleri çoğaltmak mümkün olduğu gibi, derlemden elde edilebilecek verilerin sınırı kullanıcının amacı ve hayal gücü ile ilişkilidir. Derlemler her soruya cevap vermezler, ama doğru sorulmuş sorulara cevap vermemiş olmaları da ayrıca değerlendirilmesi gereken bir durumdur. Hunston (2002), "derlemlerden elde edilmiş verilerin olgular olarak değil çıkarımlar olarak görülmesi gerektiğini” ifade etmektedir (s.23). Bunun nedeni derlemlerin bir dil yapısını kurmanın mümkün olup olmadığını değil, o yapının hangi ölçüde sık olduğunu söyleyebiliyor olmasıdır (Sinclair, 1991; Biber, Conrad ve Reppen, 1998). 


\section{Derlem Tasarımı}

Derlem oluşturma sürecindeki en önemli olgu, derlemin 'o dili' en üst düzeyde temsil edebiliyor olmasıdır (Sinclair, 2005). Günümüzde derlem tasarımında kullanılan yöntemler, genelde 'elektronik ortamdaki metinleri bir araya getirme', 'optik tarayıcılar kullanarak metinleri elektronik ortama taşıma', 'klavye aracılığıyla metinleri elektronik ortama taşıma' ve 'kaydedilmiş konuşmaları bilgisayar aracığı ile yazılı dile dönüştürme' olarak stralanabilir (McEnery ve Wilson, 1997).

Derlemin tasarımı aşamasında en önemli süreç derlemin tasarımının hangi ölçütlere göre yapılacağıdır. Bu ölçütler belirlenirken dikkat edilmesi gereken unsurlar, tasarlanacak olan derlemin türüne ve büyüklüğüne karar verme, derleme dâhil edilecek metinlerin çeşitliliğini sağlama, metinleri elde etme, metinleri elektronik ortama dönüştürme ve kaydedilmiş metinleri etiketlendirmedir (Biber ve diğerleri, 1998; Hunston, 2002; Meyer, 2002; Sinclair, 1992). Derlem tasarımının kuramsal boyutuna geçmeden önce tasarım sürecinde kullanılan bazı teknik kavramları da açıklamak gerekmektedir. Hunston'ın (2002) ve Meyer'in (2002) derlemin içeriğini 'etiketlendirme' (corpus annotation) başlığı altında sundukları bu kavramlar; işaret / sözcük (token), tür (type), bir kere görülen sözcük (hapax), baş/ön kelime (lemma), ayriştırma (parsing) ve dilbilgisel kodlama (tagging) olarak sıralanabilir. Aşağıdaki metin bu kavramları örneklendirmek için kullanılmıştır.

Araştırmanın temel amacı, İngilizce eğitimi alan ögrencilerin sözcük ve ilişkili-sözcük (deyim, bileşik fiil, fiil-edat kullanımı, vb) ediniminde veri yönlendirmeli öğrenme yaklaşımının etkililiğini bir e-ögrrenme ortamı ile sinamaktır. Aynı zamanda, ögrencilerin güncel yabancs dil ögretim teknolojilerini tanımalar, kullanmalar ve onlardan yararlanmaları amaçlanmaktadır. Biraz daha açı bir şekilde ifade etmek gerekirse, araştırmanın amacl, bilgisayara dayalı yabancı dil ögretimi alanında derleme dayal dil ögretim materyalleri kullanımının öğrencilerin sözcük ve ilişkili-sözcük edinimleri üzerinde nasıl bir etkiye sahip olduğunu ortaya koymaktır.

Örneğin, araştırmacı tarafından çalışmasının amacının ortaya konduğu yukarıdaki metnin bir Türkçe akademik yazılı dil derlemi için 
etiketlendirileceğini varsayarsak, bu metinde yer alan noktalama işaretleri ve aralıklarla birbirlerinden ayrılmış olan toplam sözcük sayısı 73'tür. $\mathrm{Bu}$ rakam, metindeki 'token' sayısı olarak anlamlandırılır. Metindeki 73 sözcükten tekrar eden sözcüklerin tek sözcük olarak sayıldığı durumda ise 'type' elde edilir. Bazı sözcükler metinde sadece bir kez geçmişlerdir, bu sözcüklere de 'hapax' etiketi konur. Metindeki bazı sözcükler ise 'ediniminde' ve 'edinimlerinde' örneğinde olduğu gibi aynı sözcüğün ekler yoluyla farklılaşmış biçimleridir. Bu sözcükler ise 'lemma' etiketi ile isimlendirilirler. Dilbilgisel kodlama (tagging) kavramı derlemi oluşturan metinlerdeki her bir sözcüğe dilbilgisel fonksiyonuna göre bir isim verilmesi sürecidir. Örneğin, metindeki 'alan' ve 'alanında' sözcüklerinin dilbilgisel olarak iki ayrı öğe olduğunun vurgulanması veya görülmesi için bu metinde 'dilbilgisel kodlama' yapılmalıdır. Öbeklere ayırma (parcing) ise öğesel kodlamanın öbek ve cümle boyutunda yapılarak, metinlerin cümle ve öbek olarak gruplandırılması işidir (Hunston, 2002; Meyer, 2002).

Hunston (2002) derlem oluşturmada ve bu derlemi etkin bir şekilde kullanmada başarının en önemli unsurunun derlemin içeriği olduğunu ve oluşturulacak derlemin mutlak surette bir amaca dayandırılması gerektiğini vurgulamaktadır. Sinclair (2005) derleme dâhil edilecek metinler seçilirken dikkat edilmesi gereken hususun metinlerdeki dil değil, o dilin içinde oluştuğu ortamdaki iletişimsel fonksiyonu olduğunu öne sürmektedir. Biber ve Reppen (1998) ve Hunston (2002) ise, derleme dâhil edilecek metinlerin güncellik, boyut, tür ve alan açısından bir öncelik sırasına konulması gerektiğini belirtmektedir. Derlemin büyüklüğü ile ilgili Carter ve McCarthy (1995) üst sınır olamayacağını, ama alt sınırda dikkat edilmesi gerekenin kullanıcı profiline ve derlemden beklentilerine uygun bir sözcük sayısı belirlenmesi gerekliliği olduğunu belirtmektedir. Artık alan yazında hedefe dönük ve daha sınırlı derlemlerin kullanılması gerektiğine dönük bir görüş oluşmuştur (Biber ve Reppen, 1998; Carter ve McCarthy, 1995; Sinclair, 1992). Sinclair (1992) belirli bir amaç için derlem oluşturmanın güç olduğu durumlarda genel bir derlemin bir bölümünün alınarak, belirlenmiş özel amaç için kullanılmasını önermektedir. Hunston (2002) ise, bir derlemin oluşturulma sürecinde belirlenmiş olan hedef sözcük sayısının şartlar olanak sağlasa bile aşılmaması gerektiğini belirtmiştir. Tribble (1997) ise, dil öğrencileri için tek doğru derlem olamayacağını, öğrencinin amaçları doğrultusunda birden çok derlemden yararlanması gerektiğini belirtmektedir. Şu anda derlem ve dilbilim çalışmaları için kullanılmakta olan derlemlerin sözcük sayısı yüz milyonlara ulaşmış durumdadır (İngiliz Ulusal Derlemi, (BNC): 100 milyon sözcük, İngilizce Bankası, (Bank of English): 400 milyon sözcük). 
İngiliz diline ait olan ve çoğunlukla yaygın bir kullanıma sahip derlemler Çizelge 1'de verilmiştir.

Çizelge 1. Ingiliz dili derlemleri listesi

\begin{tabular}{|c|c|c|}
\hline Derlemin Ad 1 & Sözcük Sayıs1 & Erişim \\
\hline - $\quad$ The Bank of English, BE & 524 Milyon & $\begin{array}{l}\text { http://www.collins.co.uk/books. } \\
\text { aspx?group=153 }\end{array}$ \\
\hline $\begin{array}{l}\text { - The Corpus Of Contemporary } \\
\text { American English }\end{array}$ & 385 Milyon & http://www.americancorpus.org/ \\
\hline - British National Corpus, BNC & 100 Milyon & $\begin{array}{l}\text { http://www.natcorp.ox.ac.uk/cor } \\
\text { pus/index.xml }\end{array}$ \\
\hline - $\quad$ TIME Corpus & 100 Milyon & http://www.corpus.byu.edu/time \\
\hline $\begin{array}{l}\text { - International Corpus of English, } \\
\text { ICE }\end{array}$ & 15-20 Milyon & $\begin{array}{l}\text { http://www.ucl.ac.uk./english- } \\
\text { usage/ice/ }\end{array}$ \\
\hline $\begin{array}{l}\text { - International Corpus of Learner } \\
\text { English, ICLE }\end{array}$ & 2 Milyon & Ücretli \\
\hline $\begin{array}{l}\text { - LOB (Lancaster-Oslo/Bergen ) } \\
\text { Corpus }\end{array}$ & 1 Milyon & Ücretli \\
\hline - The Brown Corpus & 1 Milyon & $\begin{array}{l}\text { http://www.lextutor.ca/concorda } \\
\text { ncers/concord_e.html }\end{array}$ \\
\hline
\end{tabular}

Stubbs (1996) derlemlerin kullanılmaya başlanmasının, dil öğretimini de içine alan uygulamalı dilbilim alanındaki, önemini teleskopun keşfinin astronomi alanına getirdiği boyutla değişmeceli (metaforik) bir şekilde örneklendirmektedir. Stubbs'a (1996) göre, derlem uzay, derleme erişimi ve onu yorumlamayı sağlayan 'sıklık listeleri' ve 'metin analiz yazılımı çıktıları' da teleskop işlevi görmektedir. Hunston (2002) derlemlerin, yabanc1 dil öğrencilerine o dili ana dili olarak konuşan öğretmenlerin 'sezgilerine' kıyasla çok daha güvenilir bilgi sunduğunu iddia etmektedir. Hunston'a (2002) göre, bir dili ana dil olarak konuşan öğretici hayatı boyunca o dilin birçok boyutuna maruz kalmıştır, ama öğrenen bütün bu dil deneyimlerini geriye dönük olarak ayrıntılı bir şekilde göremez, bu nedenle, derlemler dil yapılarını 'öğreticinin sezgisinden' daha objektif bir şekilde farklı bağlamlardaki kullanış farklılıkları ile birlikte göz önüne serebilme avantajına sahiptirler. Cook (2001), bir dil yapısının belli bir bağlamda kullanılabileceği veya kullanılamayacağg ile ilgili olarak dil öğreticisinin sezgisinin yetersiz bir veri olduğunu ve öğrencilerin derlemlerden elde edecekleri çıkarımlarla çok daha gerçek ve bağlamlı bilgiye erişebileceklerini belirtmektedir. Sinclair (1997) ve Granger (1998) ise, derlem kullanımının özellikle ilişkili sözcüklerin tespitinde ve öğreniminde önemli bir avantaj sunduğunu öne sürmekte ve bazı ilişkili sözcüklerin (painfully clear, readily available) ana dil konuşucuları tarafından bile fark 
edilemeyebildiğini ifade etmektedir. Diğer taraftan Halliday (1993) ise, derlemlerin dil öğretimine sağladığı en önemli yararı, hangi dilbilgisi yapılarının daha öncelikli olarak öğretilmesi gerektiği ile ilgili en güvenilir bilgiyi sağlamaları olarak tanımlamaktadır. Biber ve diğerleri (1998) derlem kullanımının dil öğretimi alanına dilin kuramsal yapısı yerine iletişimsel ortamlarda kullanılan formunu esas alarak yeni bir boyut kazandırdığını belirtmektedirler. Benzer olarak Flowerdew (1993) yabancı dil öğrenen kişilerin başkaları tarafından üretilmiş metinlerden yararlanmalarının günümüzde artık kaçınılmaz olduğunu ifade etmektedir.

Krieger (2003) derlemlerin dil öğretimine dönük potansiyel kullanım alanlarını: Ders izlencesi hazırlama, ders ve değerlendirme materyali geliştirme, ders içi etkinlikleri hazırlama olarak sıralamaktadır. Barlow (1992) ve Willis'e (1998) göre derlemlerden yararlanarak, dil öğrencilerine öğrenci dili ve doğal dil arasındaki farklar, sözcük dizilişi ile ilgili kurallar, kullanabilecekleri yararlı sözcük öbekleri, yazılı ve sözlü dil arasındaki farklar ve belli söylem alanlarında daha yaygın kullanılan dil yapıları öğretilebilir. Tribble ve Jones (1990) derlemlerin dil öğretiminde kullanımı için iki boyuttan bahsetmektedirler. Bunlar, öğreticinin ders ve değerlendirme materyali hazırlamak için derlemlerden yararlanması, bir diğeri de öğrencilerin doğrudan derlem ve ürünleri ile karşı karşıya getirilerek kendi dil öğrenim amaçları doğrultusunda derlemlerden yararlanmalarıdır. (McEnery ve Wilson, 1997). Bu çalışma ise yukarda bahsedilen ikinci amaca bir başka deyişle öğrencilerin doğrudan derlem ve ürünleri ile karşı karşıya getirilmelerine hizmet etmektedir.

Gavioli (1997) derlem kullanımının dil öğretimi alanına entegre edilmesi durumunda elde edilecek verimin en önemli boyutunun öğrenciyi aktif bir araştırmacıya dönüştürmesi olarak ifade etmekte ve bu düşüncesini Johns'un (1991a), "araştırma sadece araştırmacılara bırakılamayacak kadar ciddi bir iştir" yaklaşımına bağlamaktadır (s.83). Barnett (1993) derlemler aracılığıyla öğrencinin dile bir araştırmacı bakış açısı ile yaklaşması ve kendi öğrenme soru ve sorunlarına çözüm bulmaya çalışması için öğreticinin kolaylaştırıcı ve yönlendirici rolünün önemine vurgu yapmaktadır. Leech (1997) ise derlemlerin dil ögretiminde; derlemler hakkında bilgi vermek, öğrenciye derlemlerden nasıl yararlanılması gerektiğini öğretmek ve öğretimi daha etkili kılmak için derlemlerden yararlanmak şeklinde üç farklı amaç için kullanılabileceğini ifade etmektedir. Gavioli (1997) derlem kullanımının öğrenciyi çok daha bilgili kıldığını vurgulamak için dil öğretiminde derlem ve sözlük kullanımlarını karşılaştırmakta, sözlük kullanımının öğrenciyi zaten hazır olan bilgiye ulaştırdığını, ama derlem ürünlerini incelerken öğrencinin kendi sayıltılarını oluşturmak, sınamalar 
yapmak, bağlantılar kurmak, çıkarımlar yapmak zorunda kaldığını, böylece daha kalıcı ve bağlamlı bilgiler elde ettiğini öne sürmektedir. Bu düşüncesini ise derlemlerle çalışan öğrencilerin sorularına sözlüklerde olduğu gibi hemen cevap bulamamaları ve cevap bulma sürecinin sonuç bölümü olmak yerine başlangıç noktasını oluşturduğu fikrine dayandırmaktadır.

Derlemlerden yararlanmanın dil öğrenimindeki olumlu etkisine atıfta bulunan ve yukarıda ayrıntılı bir şekilde tartışılan alan yazın doğrultusunda bu çalışma, Moodle öğrenme yönetim sistemine iliştirilen çevrimiçi derlem sayfaları ve çevrimiçi sözlük ile çalışan öğrencilerin öğrenme yönetim sisteminde gezinim süreleri ile yabancı dilde sözcük ve ilişkili sözcük bilgisi türlerinin gelişimi arasındaki ilişkiyi ortaya koymayı amaçlamaktadır.

\section{YÖNTEM}

Çalışmada, yarı deneysel araştırma deseni kullanılmıştır. Çalışmanın katılımcılarını 2008-2009 öğretim yılında, Ankara Üniversitesi Tıp Fakültesi I. sınıfta öğrenim gören 68 öğrenci oluşturmaktadır. Çalışmanın araştırma soruları aşağıda verilmiş̧ir.

1.Öğrencilerin öğrenme yönetim sistemi üzerinden geliştirilmiş olan derslerde gezinim süreleri ile yabancı dilde sözcük edinimleri ve sözcükler arası anlamsal ilişkileri kavramaları arasında harhangi bir ilişki var mıdır?

2.Veri yönlendirmeli öğrenme yaklaşımı doğrultusunda öğrenim gören öğrencilerin öğrenme yönetim sistemindeki gezinim süreleri ile yabanc1 dilde sözcük edinimleri ve sözcükler arası anlamsal ilişkileri kavramaları arasında harhangi bir ilişki var mıdır?

3.Çevrimiçi sözlük kullanarak öğrenim gören öğrencilerin öğrenme yönetim sistemindeki gezinim süreleri ile yabancı dilde sözcük edinimleri ve sözcükler arası anlamsal ilişkileri kavramaları arasında harhangi bir ilişki var midir?

$\mathrm{Bu}$ çalışmada deney grupları için çevrimiçi ortamda açık kaynak kodlu bir öğrenme yönetim sistemi olan MOODLE (Modular-Object-OrientedDynamic-Learning-Environment, Esnek Nesne Yönelimli Dinamik Öğrenme Ortamı) üzerinden iki ayrı sözcük öğretimi dersi geliştirilmiştir.

Veri yönlendirmeli öğrenme yaklaşımı doğrultusunda geliştirilen ve 1 . deney grubunun yer aldığ 1 dersin ad1, 'Data-driven Learning' (Veri Yönlendirmeli Öğrenme), 2. deney grubunun yer aldığı dersin adı ise 'Online Dictionary Use' (Çevrimiçi Sözlük Kullanımı) olarak belirlenmiştir. Her iki derste, öğretilmesi hedeflenen ayn 50 sözcüğün aynı içerik ve 
sırayla 10'ar sözcük olarak sınıflandırıldığı beş alt parçaya sahiptir. Modüllerdeki sözcük sayısının 10 olarak belirlenmesinde Ankara Üniversitesi Tıp Fakültesinde görev yapan dört İngilizce okutmanının görüş ve onayları dikkate alınmıştır. Derslerdeki her bir parça yaklaşık 80 dakikalık bir oturum süresine sahiptir. Çalışmaya katılan 68 öğrenci, iki saati pazartesi, iki saati çarşamba günü olmak üzere haftada dört saatlik, katılım mecburiyeti bulunan, yabancı dil (İngilizce) dersinin kayıtlı öğrencileridir. Dolayısıyla, oturum süreleri öğrencilerin ders sürelerine uygun olarak belirlenmiştir.

Derslerde aynı etkinlikler aynı sıra ve içerikte sunulmuştur. Derslerin her bir oturumu üç aşama altında tanımlanabilir. Her iki derste de bütün oturumların ilk aşaması, oturumun amacını ve hedeflenen sözcüklerin tanıtılmasını sağlayan bir yönergeden oluşmaktadır. Bir sonraki aşama ileride ayrıntılı olarak tanımlanacak olan derslerin kendilerine özgü etkinliklerini içermektedir. Derslerin birbirinden farklılaştıkları tek boyut, sözcük öğrenimi sürecinde yararlandıkları çevrimiçi kaynaklardır. Üçüncü aşama ise her iki derste de yer alan ve ögrrencilerin aktif ve pasif sözcük bilgilerini de ölçmeyi amaçlayan iki eşleştirmeli 'küçük sınav' (quiz) etkinliğidir. Küçük sınav etkinliklerinde, her iki grupta da, öğrencilerin soruları yanıtlama girişimleri tek bir kereyle sınırlandırılmış, aynı soruya ikinci bir kez yanıtlama olanağı sunulmamıştır.

\section{Veri Toplama Araçları}

Çalışmada, akademik sözcük ve sözcükler arası anlamsal ilişki bilgisini ölçmek amacıyla, hem akademik sözcükleri hem de edat öbeklerini içeren iki ayrı ölçme arac1 ön ölçüm, son ölçüm ve izleme ölçümü aracı olarak kullanılmıştır. Çalışmada kullanılan bütün veri toplama araçlarının güvenirlik ve geçerlik çalışmaları Ankara Üniversitesi Tıp Fakültesi I. sınıfında öğrenim gören ve asıl uygulamaya katılanların dışındaki öğrencilerin katılımlarıyla yapılmıștır. Ayrıca, orijinal dili İngilizce olan sözcük bilgisi ölçme aracının uyarlanması sürecinde, araçlar iki İngilizce okutmanı tarafindan Türkçe'ye çevirilmiş ve daha sonra bu çeviriler iki ayrı İngilizce okutmanı tarafından tekrar İngilizce'ye çevrilerek orijinal metinlerle tutarlılık içinde olup olmadıkları denenmiştir.

Çalıșmada kullanılacak sözcüklerin belirlenmesi için 570 sözcükten oluşan Akademik Sözcük Listesi (Coxhead, 2000) çalışmanın yürütüldüğ̈̈ Ankara Üniversitesi Tıp Fakültesinde görevli üç, Ankara Üniversitesi İngilizce Hazırlık Okulunda görevli iki İngilizce Okutmanı tarafından çalışmanın katılımcıları olan hazırlık eğitimi almış veya hazırlık eğitiminden yeterlik sınavı ile muaf olmuş olan Tıp Fakültesi I. sınıf öğrencilerinin daha önceki yabancı dil öğrenim süreç ve materyallerinde karşılaşma ihtimalleri dâhilinde değerlendirilmiştir. Uzmanların verdiği ortalama puanlar üzerinden 
artan bir ölçekte sıralanan akademik sözcüklerden bilinme açısından kritik eşik olan 2,5 düzeyine kadar olanlardan seçkisiz olarak 30 adet sözcük belirlenmiştir. Çalışmada veriler, Wesche ve Paribakht (1996) tarafından geliştirilen Sözcük Bilgisi Ölçeği (SBÖ) ve araştırmacılar tarafından geliştirilen 'İlişkili Sözcük Bilgisi' ölçme testi aracılı̆̆gyla toplanmıştır.

\section{Sözcük Bilgisi Ölçeği}

Wesche ve Paribakht (1996) tarafından geliştirilen sözcük bilgisi ölçeği (Vocabulary Knowledge Scale), ilgili diğer ölçeklere kiyasla sözcük bilgisinin değerlendirilmesinde daha somut veriler elde edilmesine olanak sağlamaktadır. Sözcük Bilgisi Ölçeği, Çizelge 2'de verilmiştir.

Çizelge 2. Sözcük bilgisi ölçeği (SBÖ)

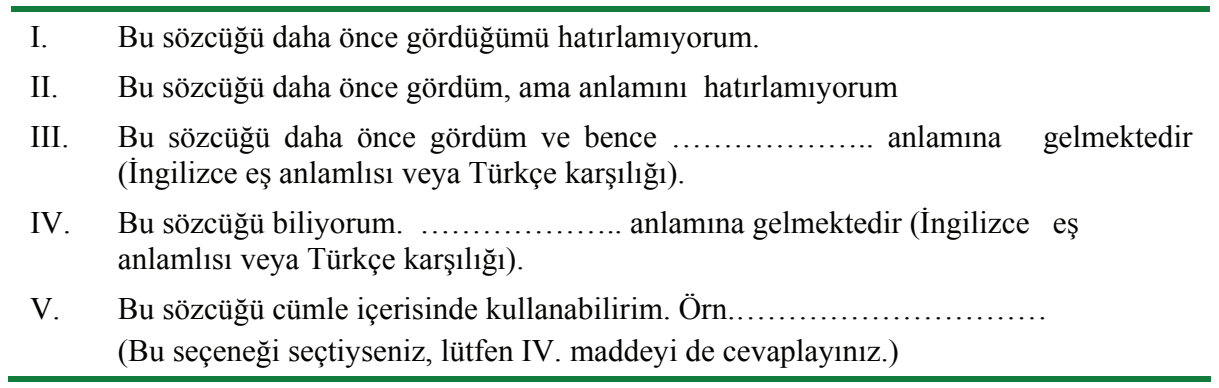

Bilişsel bir ölçek olan SBÖ Türkçe'ye uyarlanmış ve geçerlik ve güvenirlik çözümlemeleri yapılmıştır. Bu kapsamda ölçeğin Cronbach Alpha güvenirlik katsayısı .871 olarak bulunmuştur. Diğer taraftan, beşli bir yapıya sahip olan ölçek faktör çözümlemesine tabi tutulmuş ve faktör yük değerleri incelenerek, ölçeğin çalışmayan madde içerip içermediğine bakılmıştır. Faktör çözümlemesi sonucunda, madde faktör yük değeri .30'un altında hiçbir madde bulunmadığı gözlenmiş ve maddelerin tamamına esas uygulamada yer verilmesi gerektiğine (Büyüköztürk, 1999) karar verilmiştir. Ölçeğin, Kaiser-Meyer-Olkin (KMO) değeri ise .791 olarak tespit edilmiştir. Bu değer alan yazında kabul edilebilir ölçüde değerlendirilmektedir (Kaiser, 1974; Field, 2000; Pallant, 2002). Ölçekte açıklanan toplam varyansın 62.287, Barlett'in (1993) küresellik ölçümü değerinin ise 300 olduğu gözlenmiştir. Açıklanan toplam varyans miktarı alan yazında kabul edilebilir ölçüde değerlendirilmektedir (Henson ve Roberts, 2006).

Görünüş ve yap1 geçerliği içinse, ön uygulama sürecine katılan öğrencilerden ölçek ve maddelerin ifade biçimleri ile ilgili yazılı geri bildirim alınmış ve 2 ölçme değerlendirme uzmanı ile 2 İngilizce öğretim elemanının görüşlerine başvurulmuştur. 


\section{İlişkili Sözcük Bilgisi Ölçme Aracı}

Araştırmacı tarafından geliştirilen ve çoktan seçmeli olan iliş̧ili sözcük bilgisi ölçme aracı, verilen sözcükten sonra anlamsal olarak kullanılma ihtimali en yüksek seçeneğin belirlenmesi amacını taşımaktadır. Araçta kullanılan seçenekler (çeldiriciler ve doğru yanıt) İngiliz Ulusal Derlemi (BNC) üzerinde yapılan ilişkili sözcük incelemeleri sonucunda belirlenmiştir. Her bir madde (sözcük veya ilişkili sözcük) için derlemde maddenin sağ tarafiyla (sözcükten sonra kullanılabilen) anlamsal ilişki oluşturan bütün sonuçlar incelenmiş ve derlem sonucunda maddeyle en s1k ilişki derecesine sahip sözcük doğru yanıt olarak belirlenmiştir. Diğer seçenekler (çeldiriciler) için ise bütün çevrimiçi İngilizce derlemlerinde ve GOOGLE arama motorunda hiçbir anlamsal ilişkiye rastlanmamış olması koşulu gözetilmiştir.

İlişkili sözcük bilgisi ölçme aracının geçerlik ve güvenirlik çözümlemeleri yapılmıştır. Bu kapsamda ölçeğin KR 20 güvenirlik katsayısı. 857 olarak tespit edilmiştir. Görünüş ve yapı geçerliği içinse, ön uygulama sürecine katılan öğrencilerden ölçek ve maddelerin ifade biçimleri ile ilgili yazılı geri bildirim alınmış ve 2 ölçme değerlendirme uzmanı ile 2 İngilizce öğretim elemanının görüşlerine başvurulmuştur. Diğer taraftan, doğru yanlış şeklinde değerlendirilmesi gereken bir yapıya sahip olan aracın madde analizleri yapılmıştır. Buna göre, madde toplam test korelasyonu sonucu madde ayırt ediciliği değeri .20'nin altında sadece bir madde bulunduğu gözlenmiştir. Ölçme aracındaki maddelerin aynı zamanda haftalık etkinliklerde yer alan maddeler olması ve bir bütün olarak ele alınmaları gerektiğinden bu madde ölçme aracından çıkartılmamıştır. Ancak, madde ayırt ediciliği hususunda sorunlu olan madde ilişkili sözcük bilgisi ölçümü ile ilgili çözümlemelere dâhil edilmemiştir.

\section{BULGULAR}

Araştırmada elde edilen veriler, SPSS 17.0 (Sosyal Bilimler için İstatistik Programı) programı ile çözümlenmiştir. Bu bölümde, öğrencilerin öğrenme yönetim sisteminde bulunma süreleri (dakika) ile akademik sözcükleri ve edat öbeklerini edinimleri arasındaki ilişkiye dönük bulgular, kısmi korelasyon analizi yöntemiyle çözümlenmiş ve çizelgeler halinde sunulmuştur. Çözümleme sonuçları, öncelikle çalışma gruplarının tamamı üzerinden, daha sonra ise, ayr1 ayrı D1(Veri Yönlendirmeli Öğrenme) ve D2 (Çevrimiçi Sözlük Kullanımı) grupları üzerinden görselleştirilmiş ve tartışılmıştır.

Grupların ön ölçüm puanları kontrol edildiğinde sistemde bulunma süreleri ile ölçme araçlarından elde ettikleri son ölçüm puanları arasındaki 
ilişkiye dair kısmi korelasyon analizi sonuçları çizelge 3'te görselleştirilmiştir. Buna göre, çalışmaya katılan öğrencilerin, grup ayrımı olmaksızın, öğrenme yönetim sisteminde bulunma süreleri ile SBÖ son ölçüm puanları arasında pozitif yönde .32'lik bir ilişki olduğu belirlenmiştir $(\mathrm{p}<.05)$. Başka bir ifadeyle, öğrencilerin sistemde bulunma süreleri arttıkça, SBÖ'den elde ettikleri puanlarda da artış gözlenmiştir. Diğer taraftan, öğrencilerin tümünün öğrenme yönetim sisteminde bulunma süreleri ile İSB son ölçüm puanları arasında herhangi bir ilişki olmadığı sonucuna ulaşılmıştır $(\mathrm{r}=.05, \mathrm{p}>.05)$.

Çizelge 3. Grupların ön ölçüm puanları kontrol edildiğinde sistemde bulunma süreleri ile ölçme araçlarından elde ettikleri son ölçüm puanları arasındaki iliş̧kiye dair kismi korelâsyon analizi sonuçları

\begin{tabular}{cc}
\hline & SBÖ SON ÖLÇÜM \\
\hline SBS & $\mathrm{r}=, 3251$ \\
& $\mathrm{p}=, 008$ \\
\hline & İSB SON ÖLÇÜM \\
\hline SBS & $\mathrm{r}=, 0550$ \\
& $\mathrm{p}=, 663$ \\
\hline
\end{tabular}

Veri yönlendirmeli öğrenme grubundaki öğrencilerin ön ölçüm puanları kontrol edildiğinde sistemde bulunma süreleri ile ölçme araçlarından elde ettikleri son ölçüm puanları arasındaki ilişkiye dair kısmi korelasyon analizi sonuçları Çizelge 4'de verilmiştir. Buna göre, veri yönlendirmeli öğrenme grubundaki öğrencilerin öğrenme yönetim sisteminde bulunma süreleri ile SBÖ son ölçüm puanları arasında öğrencilerin sistemde bulunma süreleri arttıkça, SBÖ'den elde ettikleri puanlarda da artış gözlenmiştir. Diğer taraftan, öğrencilerin tümünün öğrenme yönetim sisteminde bulunma süreleri ile ilişkili sözcük bilgisi son ölçüm puanları arasında herhangi bir ilişki olmadığ sonucuna ulaşılmıştır ( $\mathrm{p}>.05)$

Çizelge 4. Veri yönlendirmeli ögrenme grubunun ön ölçüm puanlarl kontrol edildiğinde sistemde bulunma süreleri ile ölçme araçlarından elde ettikleri son test puanları arasındaki ilişkiye dair kısmi korelâsyon analizi sonuçları

\begin{tabular}{cc}
\hline & SBÖ SON ÖLÇÜM \\
\hline SBS & $\mathrm{r}=-, 1570$ \\
& $\mathrm{P}=, 399$ \\
\hline & İSB SON ÖLÇÜM \\
\hline SBS & $\mathrm{r}=-, 0187$ \\
& $\mathrm{p}=, 921$ \\
\hline
\end{tabular}


Çevrimiçi sözlük kullanarak öğrenim gören öğrencilerin ön ölçüm puanları kontrol edildiğinde sistemde bulunma süreleri ile ölçme araçlarından elde ettikleri son ölçüm puanları arasındaki ilişkiye dair kısmi korelasyon analizi sonuçları Çizelge 5'te verilmiştir. Buna göre, çevrimiçi sözlük kullanan öğrencilerin öğrenme yönetim sisteminde bulunma süreleri ile sözcük bilgisi ölçeği son ölçüm puanları arasında ve öğrenme yönetim sisteminde bulunma süreleri ile ilişkili sözcük bilgisi son ölçüm puanları arasında herhangi bir ilişki olmadığı gözlenmiştir ( $\mathrm{p}>.05)$.

Çizelge 5. Çevrimiçi sözlük kullanan gruptaki ögrencilerin ön ölçüm puanları kontrol edildiğinde sistemde bulunma süreleri ile ölçme araçlarından elde ettikleri son ölçüm puanları arasındaki ilişkiye dair kısmi korelâsyon analizi sonuçları

\begin{tabular}{cc}
\hline & SBÖ SON ÖLÇÜM \\
\hline SBS & $\mathrm{r}=, 2764$ \\
& $\mathrm{p}=, 119$ \\
\hline & İSB SON ÖLÇÜM \\
\hline SBS & $\mathrm{r}=-, 1450$ \\
& $\mathrm{p}=, 421$ \\
\hline
\end{tabular}

Alan yazında, veri yönlendirmeli öğrenme yaklaşımına veya derlem kullanımının dil edinimi üzerindeki etkisine yönelik deneysel çalıșmaların yetersizliği ve gerekliliği üzerinde önemli bir görüş birliği bulunmaktadır. Bununla birlikte, bu çalışmanın araştırma sorunsalına ve iletim ortamına benzer bir boyutta kurgulanmış ve yapılmış herhangi bir çalışma bulunmamaktadır. İlgili diğer çalışmalar daha çok derlem ürünlerinin sınıf ortamında ya da bilgisayar destekli dil öğrenim ortamlarındaki kullanımları ile sinırlıdır. Ayrıca ulusal ve uluslar arası alan yazındaki diğer derlem bağıntılı çalışmalar daha çok dilbilgisi ve yazım becerisini hedef almışlardır. Derlem ve çevrimiçi sözlük sayfalarında gezinim süreleri ile sözcük edinimi ve sözcükler arası ilişkilerin kavranması bağlamı dışında, mevcut çalışma ile en fazla benzerlik gösteren çalışmalar Cobb'a (1997) ve Supatranont'a (2005) aittir. Ancak Supatranont'nun (2005) çalışması, metin analiz yazılımı etkinliklerini ihtiva etmesi ve sonuçlarının kullanımını desteklemesi bakımından mevcut çalıșmayla benzerlik taşımakta, fakat hem sınıf içi öğrenme ortamı hem de çevrim dışı MAY araçları kullanması bakımından farklılaşmaktadır. Cobb'un (1997) çalışması ise, mevcut çalışma ile kullanılan etkinlikler ve daha önce bilinmeyen sözcüklerin öğretilmeye çalışılması bağlamında benzerlikler taşımaktadır. Diğer taraftan Cobb'un çalışması çevrim dışı bir ortama sahipken ve değerlendirme sınıf ortamında 
yapılmışken, mevcut çalışma bütünüyle çevrimiçi bir öğrenme ortamında gerçekleştirilmiştir.

\section{TARTIŞMA ve SONUÇ}

Grupların öğrenme yönetim sisteminde bulunma süreleri ile akademik sözcükleri ve edat öbeklerini edinimleri arasındaki ilişki bakımından, bulgulara dayalı olarak grupların sistemde bulunma süreleri arttıkça, sözcük bilgisi düzeyi ile ilgili ölçümlerden elde ettikleri puanlarda artış olduğu gözlenmiştir. Diğer taraftan, grupların sistemde bulunma süreleri ile sözcükler arası anlamsal ilişkileri kavramaları arasında herhangi bir ilişki olmadığı sonucuna ulaşılmıştır.

Bilgi ve iletişim teknolojilerinin insan hayatının hemen her alanını etkilediği günümüzde, bilgisayar destekli dil öğrenimi, geleneksel öğretimin sınırlılıklarını ortadan kaldırmak suretiyle öğrencilerin bireysel öğrenme gereksinimlerini karşılama, öğretmene bağımlılığını en az seviyeye indirme ve öğrenme yaşantılarını zenginleştirme yoluyla daha etkili bir öğrenme ortamı oluşturmayı amaçlamaktadır. Yabancı dil eğitiminin geleceği olarak değerlendirilen bilgisayar destekli dil öğrenimine dönük çalışmaların sonuçları dil öğrenimi paydaşlarına daha etkili öğrenme ortamı sağlama adına yeni bakış açıları sunmaktadır.

Geleneksel öğretim kuramlarına bağlı yabancı dil öğretmenleri, bilgisayar destekli dil öğrenimiyle ilgili bazı çekinceler taşımaktadırlar. $\mathrm{Bu}$ durum bilgisayar destekli dil öğreniminin öğretmenin geleneksel rolünü çalma, hatta yok etme potansiyeline sahip olduğu düşüncesi ile açıklanabilir. Ancak, bilgisayar destekli dil öğrenimi, öğretmeni eğitim-öğretim ortamından tamamen dışlayan bir tehdit olarak değil, ona üst düzey işlev kazandırmayı hedefleyen bir ortam olarak algılanmalıdır. Bilgisayar destekli dil öğrenimi alanında yapılacak çalışmaların, yabancı dil öğretmenlerini, teknolojinin dil öğretim ortamlarında etkili bir şekilde kullanılabileceğine dair güdüleyebileceği öngörülmektedir.

Yabancı dil öğrenimi sürecinde özgün dil materyallerinin kullanılması önemli bir gerekliliktir. Dili oluşturan araçların ve kullanım anında ortaya çıkan farklılıkların, anlam kaymalarının, mecaz yapıların ve hedef dilin kendi doğal ortamında incelenmesi, öğrenimin etkililiğini arttırmaktadır. $\mathrm{Bu}$ doğrultuda, özgün dil ürünleri kullanılarak oluşturulan öğrenim materyallerinin önemi daha iyi anlaşılmaktadır. Öğrenci açısından bakıldığında ise, bilgisayar destekli dil öğrenimi etkinlikleri öğrenmeye ayrılan zamanı ve öğrenme isteğini arttırıcı bir güce sahiptir. Bu çalışmanın 
kuramsal altyapısını oluşturan veri yönlendirmeli öğrenme yaklaşımı bilgisayar ortamında öğrencilerin kendi özgün dil araştırmalarını yapmalarını beklemekte ve kendi öğrenme süreçlerinin sorumluları olmalarını sağlamaktadır.

$\mathrm{Bu}$ araştırma ile veri yönlendirmeli öğrenme yaklaşımının yabancı dil öğretimi alanında bilgisayara dayalı materyal geliştirme ve öğrencilerin değerlendirilmesi alanlarında nasıl kullanılabileceği ile ilgili olarak yabancı dil öğretimcilerine, dil araştırmacılarına ve öğrencilere bir fikir sunulması amaçlanmıştır. Bu nedenle, bu çalışma, bundan sonra bilgisayara dayalı dil öğrenim programlarının oluşturulması sürecinde derlemlerden ve öğrenme yönetim sistemlerinden yararlanılması gerekliliğinin dayanağını oluşturacaktır. Bağlantılı olarak, çalışma, dil öğretim tasarımcılarına, metin analiz yazılımlarının yüz yüze eğitim ortamlarındaki kullanımlarına alternatif olarak bilgisayar destekli dil öğrenimi alanında nasıl kullanılması gerektiğine dair çıkarımlar sunacaktır.

\section{KAYNAKLAR}

Ball, C. N. (1996). Tutorial Notes: Concordances and Corpora. http://www.georgetown.edu/cball/corpora/tutorial.html (Alınma Tarihi: 02 Ağustos 2007)

Barlow, M. (1992). Using Concordance Software in language Teaching and Research. In Shinjo, W. et al. Proceedings of the Second International Conference on Foreign language Education and Technology. (365-373) Kasugai, Japan: LLAJ \& IALL.

Barnett, L. (1993). Teacher off: Computer technology, guidance and selfaccess. System, 21(3), 299.

Biber, D., S. Conrad, \& R. Reppen. (1998). Corpus linguistics: Investigating language structure and use. Cambridge: Cambridge University Press.

Büyüköztürk, Ş. (1998). Kovaryans analizi: Varyans analizi ile karşılaştırmalı bir inceleme. Ankara Üniversitesi Eğitim Bilimleri Fakültesi Dergisi, 31(1), 91-105.

Carter, R. \& McCarthy, M. (1995). Grammar and the spoken language. Applied Linguistics 16(2), 141-158.

Cobb, T. (1997). Is there any measurable learning from hands-on concordancing? System, 25(3), 301-315. 
Cook, V. (2001). Using the first language in the classroom. Canadian Modern Language Review, 57, 402-423.

Coxhead, A. (2000). A new academic word list. TESOL Quarterly, 34(2): 213-238.

Dunteman, G. H. (1989). Principal Components Analysis. Sage Publications, Newbury Park, California, USA.

Field, A. (2000). Discovering statistics using SPSS for Windows. LondonThousand Oaks- New Delhi. Sage Publications.

Flowerdew, J. (1993). Concordancing as a tool in course design. System, 21(2), 231-244.

Gavioli, L. ( 1997). "Exploring text through the concordancer: Guiding the learner." In A. Wichman, et al. (eds.), Teaching and Language Corpora (pp. 83-99). London and New York: Longman.

Granger S. (1998). Learner English on computer. Addison Wesley London $\&$ New York. Longman.

Halliday, M. A. K. (1993). Towards a language-based theory of learning. Linguistics and Education 5(2), 93-116.

Henson, R. K. \& Roberts, J. K. (2006). Exploratory factor analysis reporting practices in published psychological research: Common errors and some comment on improved practice. Educational and Psychological Measurement, 66(3), 393-416.

Hunston, S. (2002). Corpora in Applied Linguistics. Cambridge: Cambridge University Pres.

Johns, T. (1991). "'Should you be persuaded": two samples of data-driven learning materials' in T. Johns \& P. King (eds.) Classroom Concordancing ELR Journal 4. (pp 1-13) University of Birmingham.

Kaiser, H.F. (1974). An index of factorial simplicity. Psychometrika, 39, 316.

Kennedy, G. (1998). An Introduction to Corpus Linguistics. London: Longman.

Krieger. H. U. (2003). SDL—a description language for building NLP systems. In Proceedings of the HLT-NAACL Workshop on the Software Engineering and Architecture of Language Technology Systems, 84-91. Canada. 
Leech, G. (1997). Teaching and language corpora: A convergence In A. Wichmann, S. Fligelstone, A. McEnery and G. Knowles (eds.) Teaching and Language Corpora. (pp. 1-23). London: Longman.

McEnery, A. \& Wilson, A. (1997). Corpora and language teaching. RECALL Journal, 9(1), 5-14.

McEnery, A. \& Wilson, A. (2001). Corpus Linguistics. Edinburgh: Edinburgh University Pres.

Meyer, C. (2002). English Corpus Linguistics: An Introduction. Cambridge: Cambridge University Press.

Pallant, J. (2002). SPSS Survival Manual. Buckingham. Open University Press.

Sinclair, J. (1991) Corpus, Concordance, Collocation. Oxford University Press.

Sinclair, J. 1992. Collins COBUILD English Usage. Birmingham University with London: Harper Collins.

Sinclair, J. (1997). 'Corpus evidence in language description' in Wichmann, Fligelstone, McEnery \& Knowles (eds.), Teaching and Language Corpora. (pp. 27-39). London and New York. Longman.

Sinclair, J. (2005). Corpus and text-basic principles. In Wynne, M. (ed.) Developing Linguistic Corpora: A Guide to Good Practice. (pp. 1-16). Oxford: Oxbow Books: (http://ahds.ac.uk/linguisticcorpora/) adresinden 23 Şubat 2006 tarihinde alınmıştır.

Supatranont, P. (2005). A Comparison of the effects of the concordancebased and the conventional teaching methods on engineering students' English vocabulary learning. Unpublished Doctoral Dissertation. Graduate School Chulalongkorn University.

Stubbs, M., (1996). Text and Corpus Analysis. Oxford, UK; Cambridge, Mass. Blackwell.

Teubert W. (2002). The role of parallel corpora in translation and multilingual lexicography. In Altenberg B. and Granger S. (eds.) Lexis in contrast. Corpus-based approaches. (pp. 189-214). Amsterdam / Philadelphia: John Benjamins Publishing Company.

Tribble, C., \& Johns, G. (1990). Concordances in the classroom. London: Longman.

Tribble, C. (1997). 'Improvising corpora for ELT: Quick and dirty ways of developing corpora for language teaching' in B. Lewandowska- 
Tomaszczyk and J. Melia (eds). Proceedings of the First International conference on Practical Applications in language Corpora. (pp. 32-41) (http://web.bham.ac.uk/johnstf/palc.htm) adresinden 27 Ağustos 2007 tarihinde alınmıştır.

Wesche, M. \& T. Paribakht. (1996). Assessing vocabulary knowledge: Depth vs. breadth. Canadian Modern Language Review, 53 (1): 13-40.

Willis, J. (1998). Concordances in the classroom without a computer, In Brian Tomlinson (Ed.) Materials development in language teaching. (pp. 44-46). Cambridge. 